\title{
Arrival time parametric imaging using Sonazoid-enhanced ultrasonography is useful for the detection of spoke-wheel patterns of focal nodular hyperplasia smaller than $3 \mathrm{~cm}$
}

\author{
NORITAKA WAKUI $^{1}$, RYUJI TAKAYAMA ${ }^{1}$, NAOHISA KAMIYAMA ${ }^{2}$, KOJIRO KOBAYASHI $^{1}$, DAIGO MATSUI ${ }^{1}$, \\ YASUSHI MATSUKIYO ${ }^{1}$, TAKENORI KANEKAWA ${ }^{1}$, TAKASHI IKEHARA ${ }^{1}$, KOJI ISHII ${ }^{1}$ and YASUKIYO SUMINO ${ }^{1}$ \\ ${ }^{1}$ Division of Gastroenterology and Hepatology, Toho University Omori Medical Center, Tokyo 143-8541; \\ ${ }^{2}$ Ultrasound General Imaging, GE Healthcare, Tokyo 191-8503, Japan
}

Received January 15, 2013; Accepted March 25, 2013

DOI: $10.3892 /$ etm.2013.1048

\begin{abstract}
It is considered difficult to make a definitive diagnosis of focal nodular hyperplasia $(\mathrm{FNH})$ of $<3 \mathrm{~cm}$ when using conventional diagnostic imaging modalities. Typical FNH imaging findings are: i) central scar formation, ii) nutrient vessels extending radially from the center and iii) the presence of Kupffer cells. In a clinical setting, identification of a spokewheel pattern formed by nutrient vessels extending radially is a key feature in the diagnosis of FNH. In this study, we investigated the detection rate of spoke-wheel patterns of $\mathrm{FNH}<3 \mathrm{~cm}$ using arrival time parametric imaging (At-PI) technology with Sonazoid-enhanced ultrasonography (US). Five patients with FNH $<3 \mathrm{~cm}$ who had undergone Sonazoid-enhanced US at the Toho University Omori Medical Center between February 2008 and March 2009 were included in the study. The mean tumor diameter was $20.2 \pm 7.2 \mathrm{~mm}$. Lesions were enhanced with $0.5 \mathrm{ml}$ Sonazoid US contrast agent and a video of the procedure was saved and used for At-PI analysis of contrast agent dynamics in FNH. Three ultrasonographic specialists examined the images and made a diagnosis of FNH based on the findings of spoke-wheel patterns. Similarly, micro-flow imaging (MFI) was performed to evaluate the contrast agent dynamics in FNH. Using MFI, FNH was diagnosed in 3 of the 5 cases by the three specialists, whereas At-PI enabled the identification of spoke-wheel patterns in all 5 cases. At-PI using Sonazoid-enhanced US is superior for detecting spokewheel patterns of $\mathrm{FNH}<3 \mathrm{~cm}$.
\end{abstract}

Correspondence to: Dr Noritaka Wakui, Division of Gastroenterology and Hepatology, Toho University Omori Medical Center, 6-11-1 Omori-nishi, Ota-ku, Tokyo 143-8541, Japan

E-mail: noriwakui@yahoo.co.jp

Abbreviations: FNH, focal nodular hyperplasia; At-PI, arrival time parametric imaging; MFI, micro-flow imaging; US, ultrasonography; CT, computed tomography

Key words: focal nodular hyperplasia, arrival time parametric imaging, micro-flow imaging, Sonazoid, contrast-enhanced ultrasonography, spoke-wheel pattern

\section{Introduction}

Focal nodular hyperplasia (FNH) is a benign hyperplastic lesion and the number of reports of FNH has been increasing owing to the widespread use of diagnostic imaging at routine medical check-ups. The characteristic imaging findings of FNH are: i) central scar formation, ii) nutrient vessels extending radially from the center and iii) the presence of Kupffer cells (1). When using an imaging modality in the diagnosis of FNH, the key is to identify the spoke-wheel pattern of nutrient vessels radiating from the center of the FNH lesion. However, with contrast-enhanced computed tomography (CT), the detection rate of tumors $<3 \mathrm{~cm}$ is reportedly as low as $3 \%$, even though the detection rate of tumors $>3 \mathrm{~cm}$ is $65 \%$ (2). With contrast-enhanced ultrasonography (US), the detection rates of tumors $>3 \mathrm{~cm},<3 \mathrm{~cm}$ and $<2 \mathrm{~cm}$ are 95,30 and $16.7 \%$, respectively (3). The detection of spoke-wheel patterns in FNH $<3 \mathrm{~cm}$ is particularly difficult, resulting in low detection rates. Currently, Sonazoid-enhanced US is commonly used to obtain detailed hemodynamic information of hepatic lesions and to make a qualitative diagnosis (4-11); however, due to the monochromatic representation of the contrast agent, detailed visual examination of the hemodynamics in small tumors and tumors with rapid blood flow is often difficult.

In this study, we used arrival time parametric imaging (At-PI), which enables color display of contrast agent dynamics in contrast-enhanced US to investigate the detection rate of spoke-wheel patterns in $\mathrm{FNH}<3 \mathrm{~cm}$.

\section{Materials and methods}

Patient background. Five patients ( 3 males and 2 females) with FNH $<3 \mathrm{~cm}$ who had undergone Sonazoid-contrast US at the Toho University Omori Medical Center in Tokyo, Japan between February 2008 and March 2009 were enrolled in the study. The mean tumor diameter was $20.2 \pm 7.2 \mathrm{~mm}$ (Table I). FNH was diagnosed on the basis of high-density signals in the early phase and iso-density signals in the equilibrium phase of abdominal $\mathrm{CT}$ as well as histological findings of $\mathrm{FNH}$, including irregular hyperplastic hepatocytes and fibrotic scarring involving abnormal blood vessels 
Table I. Patient characteristics.

\begin{tabular}{lccccc}
\hline Case & $\begin{array}{c}\text { Age } \\
\text { (years) }\end{array}$ & $\begin{array}{c}\text { Gender } \\
\text { (male/female })\end{array}$ & $\begin{array}{c}\text { Tumor diameter } \\
(\mathrm{mm})\end{array}$ & $\begin{array}{c}\text { Echo level } \\
\text { (high/low) }\end{array}$ & $\begin{array}{c}\text { Time needed to contrast } \\
\text { an entire tumor (sec) }\end{array}$ \\
\hline 1 & 47 & $\mathrm{~F}$ & 14 & Low & 1.7 \\
2 & 59 & $\mathrm{M}$ & 17 & Low & 2.5 \\
3 & 34 & $\mathrm{M}$ & 14 & Low & 2.8 \\
4 & 43 & $\mathrm{~F}$ & 28 & Low & 2.5 \\
5 & 56 & $\mathrm{M}$ & 28 & Low & 2.0 \\
\hline
\end{tabular}

in post-US biopsy. This study was performed with approval of the Ethics Committee at Toho University Omori Medical Center. Written informed patient consent was obtained from the patient.

Sonazoid-enhanced US. Ultrasonography was performed using a Toshiba Aplio XG ultrasound device (SSA-790A; Toshiba Medical Systems, Tochigi, Japan) with a $3.75 \mathrm{MHz}$ convex array probe (PVT-375 BT) at a mechanical index of 0.22-0.29. The focus was set at the bottom end of the tumors and $0.5 \mathrm{ml}$ Sonazoid (perfluorobutane; GE Healthcare, Oslo, Norway) was injected into the cubital vein. Data generated in the first $40 \mathrm{sec}$ was saved as raw data on the hard disk. US was performed by the same operator to maintain imaging consistency.

At-PI. Following US, At-PI was performed using the proprietary image analysis software of the ultrasound system. The system set the point at which the contrast agent reached the hepatic tumor as time zero and sequentially calculated the arrival time at individual pixels representing the tumor. A color map was created and automatically superimposed on a B-mode image. Then, two parametric-color scales were used to analyze color patterns and the time setting for color distribution. Parametric-color scale 1, with time $0-0.5 \mathrm{sec}$ in red and time $>0.5 \mathrm{sec}$ in yellow, was used to analyze tumors contrasted within 2 sec. Parametric-color scale 2 was used for tumors requiring $\geq 2 \mathrm{sec}$ for contrast enhancement and red, cyan and yellow were used to represent the times $0-1,1-2$ and $>2 \mathrm{sec}$, respectively (Fig. 1).

Micro-flow imaging. Following US, micro-flow imaging (MFI) was also performed using the proprietary image analysis software of the ultrasound system. The system started counting time when the contrast agent reached the tumor and the arrival time of individual pixels representing the tumor was sequentially calculated. A color map was created and automatically superimposed on a B-mode image.

Tumor assessment. At-PI video images were evaluated by three ultrasonographic specialists with extensive experience $(14,17$ and 33 years) in the contrast-enhanced US of liver diseases. The specialists had no access to the clinical background of the patients, hemanalysis, imaging findings or final diagnosis. Detection of a spoke-wheel pattern was considered a positive imaging finding. Similarly, MFI images were generated to analyze contrast agent dynamics.

\section{Results}

Case 1 (47-year-old female) had a 14-mm tumor with low echo signals in hepatic segment 8 (S8). Since it took $1.7 \mathrm{sec}$ to contrast the entire tumor, parametric-color scale 1 was used in At-PI analysis. Three ultrasonographic specialists identified a spoke-wheel pattern on the At-PI images, even though no identification was made in MFI.

Case 2 (59-year-old male) had a 17-mm tumor with low echo signals in S8. Since $2.5 \mathrm{sec}$ was required to contrast the tumor, parametric-color scale 2 was used in At-PI. Three specialists observed a spoke-wheel pattern in At-PI but not in MFI.

Case 3 (34-year-old male) had a 14-mm tumor with low echo signals in S8. Since $2.8 \mathrm{sec}$ was required for tumor enhancement, parametric-color scale 2 was used in At-PI. A positive diagnosis of FNH was made using MFI and At-PI.

Case 4 (43-year-old female) had a 28-mm tumor with low echo signals in S5. As $2.5 \mathrm{sec}$ was required for tumor enhancement, parametric-color scale 2 was used in the analysis. A positive diagnosis was made using the two imaging modalities.

Case 5 (56-year-old male) had a $28-\mathrm{mm}$ tumor with low echo signals in S3. Since it took $2.0 \mathrm{sec}$ to contrast the tumor, parametric-color scale 1 was used in At-PI analysis. A spoke-wheel pattern was identified using MFI and At-PI. Fig. 2 shows the At-PI and MFI images from all cases.

\section{Discussion}

First reported by Edmondson (12) in 1956, FNH is characterized by its high prevalence in females aged 20-50 years (76.2-88\%) (13-16) and often exists as a solitary lesion $(76.2 \%)(15,16)$. Although the pathogenesis of FNH is currently unknown, Wanless et al suggested that FNH is caused by hyperplasia of liver parenchyma in response to angiodysplasia since a number of FNH cases have involved vascular and neuroendocrine abnormalities $(17,18)$. An association with birth control pills and thyroid hormones has also been proposed; however, according to certain studies, these agents promote the growth of FNH, but do not cause FNH (19-22).

Typical imaging findings of FNH are: i) central scar formation, ii) nutrient vessels radiating from the center and iii) the presence of Kupffer cells (1). With various forms of diagnostic imaging of $\mathrm{FNH}$, it is essential to identify the spoke-wheel pattern of nutrient vessels radiating from the center of the lesion. Although $95 \%$ of $\mathrm{FNH}>3 \mathrm{~cm}$ are detected successfully, the detection of FNH $<3 \mathrm{~cm}$ is often difficult with a rate of $30 \%$ for $\mathrm{FNH}<3 \mathrm{~cm}$ and $16.7 \%$ for $<2 \mathrm{~cm}$ by 

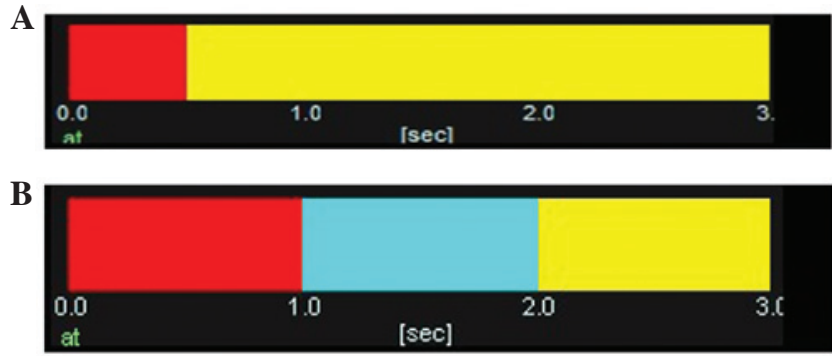

Figure 1. Color scales used in arrival time parametric imaging (At-PI) (A) Parametric-color scale 1 (red, 0-0.5 sec; yellow, $>0.5 \mathrm{sec}$ ) was used to evaluate lesions contrasted within 2 sec. (B) Parametric-color scale 2 was used for lesions requiring $\geq 2 \mathrm{sec}$ for contrast enhancement. The scale was generated with red $(0-1 \mathrm{sec})$, cyan $(0-2 \mathrm{sec})$ and yellow $(>2 \mathrm{sec})$.

contrast-enhanced US (3). Since the malignant potential of FNH has been considered negative in previous clonal studies (23-25), patients with a definitive pre-operative diagnosis of FNH are counter-indicated for surgical resection and are generally placed under observation. This also means that a pre-operative needle biopsy is essential in the diagnosis of $\mathrm{FNH}$; however, a definitive diagnosis of $\mathrm{FNH}<20 \mathrm{~mm}$ is often difficult to make (26). Furthermore, the use of needle biopsy in the diagnosis of FNH has been controversial $(2,12,27)$. For this reason, FNH patients are generally followed-up if a diagnosis of FNH is made following comprehensive imaging analysis.

Since its introduction, the ultrasound contrast agent Sonazoid has been used to thoroughly investigate the angioarchitectonic patterns of hepatic lesions whose hemodynamics were previously difficult to understand in detail (4-11). In addition, the MFI function (Toshiba Medical Systems), which was developed to analyze the angioarchitectonic patterns of hepatic lesions, has been reported to be useful $(28,29)$. However, the drawback of MFI is the difficulty associated with the evaluation of angioarchitecture and contrast agent dynamics due to rapid monochromatic enhancement of small lesions or lesions with a short contrast time. By contrast, At-PI has the advantage of displaying temporal changes in contrastenhanced imaging findings with arbitrary colors, thus having better potential for detecting the spoke-wheel patterns of FNH $<3 \mathrm{~cm}$. As anticipated, At-PI enabled us to identify spokewheel patterns visually. By contrast, it was difficult with MFI to identify spoke-wheel patterns in 2 of 5 cases, even though MFI, which traces contrast agent dynamics in detail, proved extremely useful in the evaluation of hemodynamics in relatively larger FNH or in FNH that contrasted slowly. In 1 of the 2 failed cases, it took $1.7 \mathrm{sec}$ to contrast the 14-mm lesion and the lesion in another case was $17 \mathrm{~mm}$ and took $2.5 \mathrm{sec}$ for contrast enhancement. These tumors were small and contrasted quickly. Even in these situations, the At-PI system enabled the detection of nutrient vessels radiating from the center of tumors due to the arbitrary contrast time settings. To clearly distinguish colors, a longer interval was set to analyze tumors that contrasted slowly, while a shorter interval was set for those that contrasted rapidly and this led to split-second visualization of blood vessels forming a spoke-wheel pattern.

Furthermore, while it is necessary to analyze the video to fully understand contrast agent dynamics in MFI, At-PI enables the diagnosis of FNH by means of a single, static,

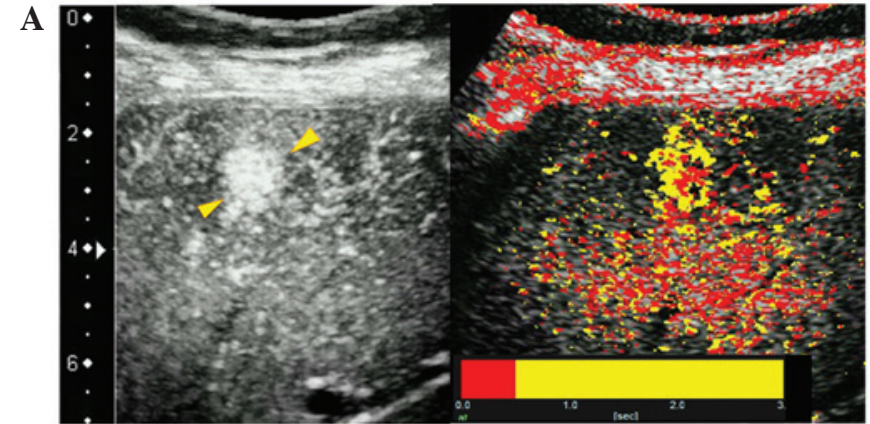

B
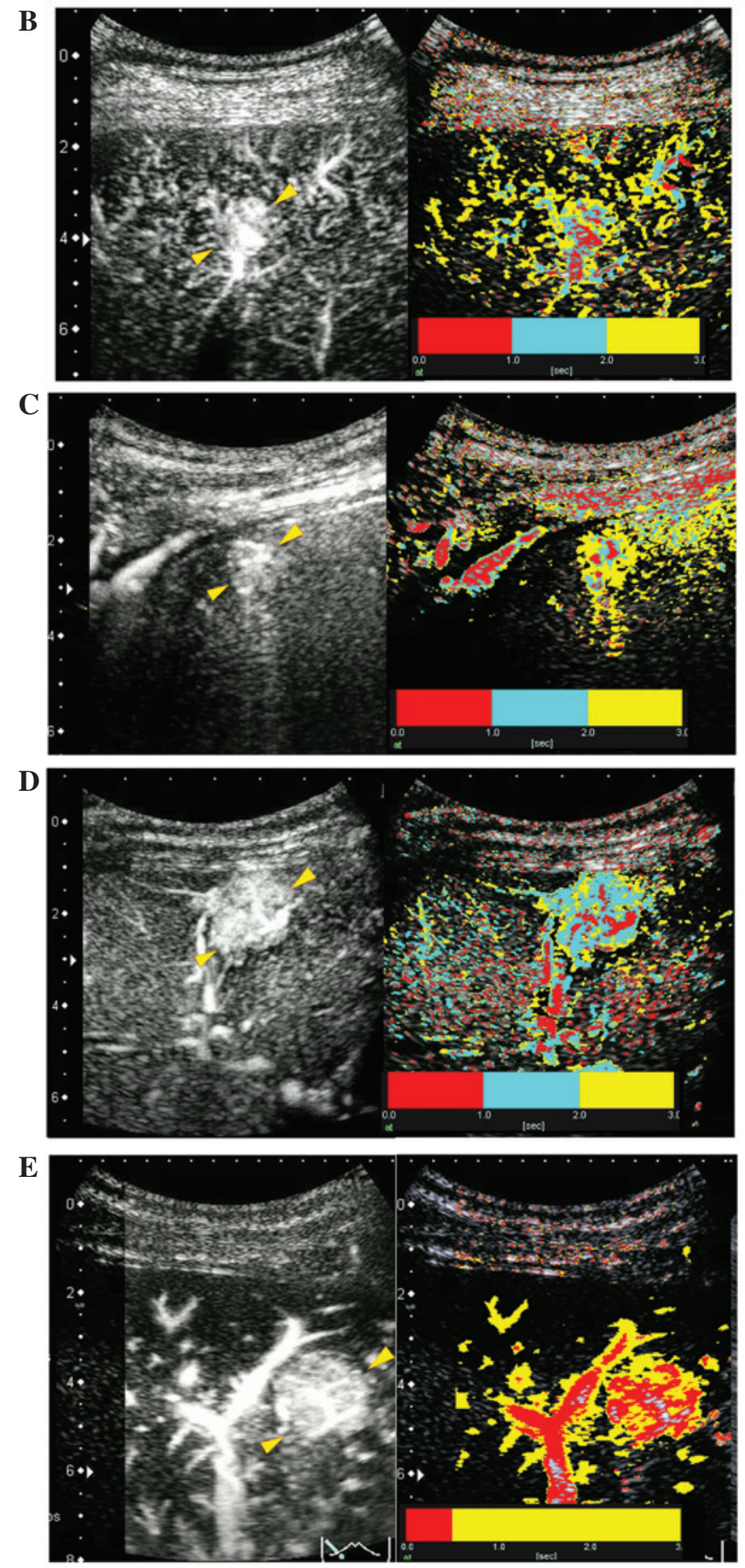

Figure 2. Ultrasound (US) imaging of focal nodular hyperplasia (FNH) in 5 cases. Left, micro-flow imaging (MFI) and right, arrival time parametric imaging (At-PI). In (A) case 1 and (B) case 2, a spoke-wheel pattern was visible in At-PI but not in MFI. In (C-E) cases 3, 4 and 5, respectively, a spokewheel pattern was visible in MFI and At-PI. Arrowheads indicate the tumor. 
color-mapped B-mode image that shows the direction and timing of contrast enhancement in the tumor. Therefore, it is easy to explain the findings of contrast agent dynamics, making the system highly useful in a clinical setting. We consider that At-PI is an effective tool for investigating the detailed hemodynamics of small hepatic tumors and tumors with rapid blood flow. At-PI using Sonazoid-enhanced US was useful for identifying spoke-wheel patterns of $\mathrm{FNH}<3 \mathrm{~cm}$.

\section{References}

1. Ueda K, Matsui O, Kawamori Y, et al: Differentiation of hypervascular hepatic pseudolesions from hepatocellular carcinoma: value of single-level dynamic CT during hepatic arteriography. J Comput Assist Tomogr 22: 703-708, 1998.

2. Brancatelli G, Federle MP, Grazioli L, Blachar A, Peterson MS and Thaete L: Focal nodular hyperplasia: CT findings with emphasis on multiphasic helical CT in 78 patients. Radiology 219: 61-68, 2001.

3. Ungermann L, Eliás P, Zizka J, Ryska P and Klzo L: Focal nodular hyperplasia: spoke-wheel arterial pattern and other signs on dynamic contrast-enhanced ultrasonography. Eur J Radiol 63 290-294, 2007

4. Takahashi M, Maruyama H, Ishibashi H, Yoshikawa M and Yokosuka O: Contrast-enhanced ultrasound with perflubutane microbubble agent: evaluation of differentiation of hepatocellular carcinoma. AJR Am J Roentgenol 196: W123-W131, 2011.

5. Hiraoka A, Hirooka M, Koizumi Y, et al: Modified technique for determining therapeutic response to radiofrequency ablation therapy for hepatocellular carcinoma using US-volume system. Oncol Rep 23: 493-497, 2010.

6. Luo W, Numata K, Kondo M, et al: Sonazoid-enhanced ultrasonography for evaluation of the enhancement patterns of focal liver tumors in the late phase by intermittent imaging with a high mechanical index. J Ultrasound Med 28: 439-448, 2009.

7. Shiozawa K, Watanabe M, Kikuchi Y, et al: Evaluation of sorafenib for hepatocellular carcinoma by contrast-enhanced ultrasonography: a pilot study. World J Gastroenterol 18: 5753-5758, 2012.

8. Kudo M: New sonographic techniques for the diagnosis and treatment of hepatocellular carcinoma. Hepatol Res 37 (Suppl 2): S193-S199, 2007.

9. Wakui N, Takayama R, Kamiyama N, et al: Diagnosis of hepatic hemangioma by parametric imaging using sonazoid-enhanced US. Hepatogastroenterology 58: 1431-1435, 2011.

10. Wakui N, Sumino Y and Kamiyama N: A case of high-flow hepatic hemangioma: analysis by parametoric imaging using sonazoid-enhanced ultrasonography. J Med Ultrasonics 37: 87-90, 2010.

11. Wakui N, Takayama R, Matsukiyo Y, et al: A case of poorly differentiated hepatocellular carcinoma with intriguing ultrasonography findings. Oncol Lett 4: 393-397, 2012.

12. Edmondson HA: Differential diagnosis of tumors and tumor-like lesions of liver in infancy and childhood. AMA J Dis Child 91: 168-186, 1956.

13. Molina EG. Benign solid lesions of the liver. In: Schiff's Disease of the Liver. Schiff ER, Sorrell MR and Maddrey WC (eds). Vol 2.9th edition. Lippincott Williams \& Wilkins, Philadelphia, PA, pp1352-1375, 2003.
14. Kerlin P, Davis GL, McGill DB, Weiland LH, Adson MA and Sheedy PF II: Hepatic adenoma and focal nodular hyperplasia: clinical, pathologic and radiologic features. Gastroenterology 84: 994-1002, 1983.

15. Nguyen BN, Fléjou JF, Terris B, Belghiti J and Degott C: Focal nodular hyperplasia of the liver: a comprehensive pathologic study of 305 lesions and recognition of new histologic forms. Am J Surg Pathol 23: 1441-1454, 1999.

16. Shen YH, Fan J, Wu ZQ, et al: Focal nodular hyperplasia of the liver in 86 patients. Hepatobiliary Pancreat Dis Int 6: 52-57, 2007.

17. Wanless IR, Mawdsley C and Adams R: On the pathogenesis of focal nodular hyperplasia of the liver. Hepatology 5: 1194-1200, 1985.

18. Wanless IR, Albrecht S, Bilbao J, et al: Multiple focal nodular hyperplasia of the liver associated with vascular malformations of various organs and neoplasia of the brain: a new syndrome. Mod Pathol 5: 456-462, 1989.

19. Baum JK, Bookstein JJ, Holtz F and Klein EW: Possible association between benign hepatomas and oral contraceptives. Lancet 2: 926-929, 1973.

20. Ishak KG: Hepatic neoplasms associated with contraceptive and anabolic steroids. In: Carcinogenic Hormones: Recent Results in Cancer Reseach. Lingeman CH (ed). Springer-Verlag, New York, NY, pp73-128, 1979.

21. Kaji K, Kaneko S, Matsushita E, Kobayashi K, Matsui O and Nakanuma Y: A case of progressive multiple focal nodular hyperplasia with alteration of imaging studies. Am J Gastroenterol 93: 2568-2572, 1998.

22. Nakamuta M, Ohashi M, Fukutomi T, et al: Oral contraceptivedependent growth of focal nodular hyperplasia. J Gastroenterol Hepatol 9: 521-523, 1994.

23. Zhang SH, Cong WM and Wu MC: Focal nodular hyperplasia with concomitant hepatocellular carcinoma. J Clin Pathol 57: 556-559, 2004.

24. Chen TC, Chou TB, Ng KF, Hsieh LL and Chou YH: Hepatocellular carcinoma associated with focal nodular hyperplasia. Virchows Arch 438: 408-411, 2001.

25. Paradis V, Laurent A, Flejou JF, Vidaud M and Bedossa P: Evidence for the polyclonal nature of focal nodular hyperplasia of the liver by X-chromosome inactivation. Hepatology 26 : 891-895, 1997.

26. Hisakura K, Yoshimi F, Asato Y, et al: Two resected cases of hepatic focal nodular hyperplasia. Liver Cancer 10: 28-33, 2004 (In Japanese)

27. Charny CK, Jarnagin WR, Schwartz LH, et al: Management of 155 patients with benign liver tumors. Br J Surg 88: 808-813, 2001.

28. Yang H, Liu GJ, Lu MD, Xu HX and Xie XY: Evaluation of the vascular architecture of hepatocellular carcinoma by micro-flow imaging: pathologic correlation. J Ultrasound Med 26: 461-467, 2007.

29. Sugimoto K, Moriyasu F, Kamiyama N, et al: Analysis of morphological vascular changes of hepatocellular carcinoma by microflow imaging using contrast-enhanced sonography. Hepatol Res 38: 790-799, 2008. 